\title{
Men as Fathers in Child Protection
}

\author{
Authors \\ Professor Marian Brandon \\ Dr Georgia Philip \\ Dr John Clifton \\ Corresponding author: \\ Professor Marian Brandon \\ Elizabeth Fry Building, Centre for Research on Children and Families, School of Social \\ Work, University of East Anglia, NR4 7TJ \\ m.brandon@uea.ac.uk
}

\section{Affiliation}

All authors are from the Centre for Research on Children and Families, University of East Anglia, UK.

\begin{abstract}
When child protection professionals struggle to engage fathers and father figures, assessments may not accurately reflect the combination of resource and risk factors men present for children they care for, potentially endangering children and excluding men. In a mixed methods study in England of fathers and their perspectives on involvement in child protection and with their children, fathers persisted as a presence in children's lives. Yet there was little intervention with men and expectations were low and gendered. The study positioned fathers in child protection dynamically, in six ways: 'marked men', 'in the frame', 'on trial', 'good enough', 'safe pair of hands' and 'on the fringe'. Encouragingly, most movement was towards positive change and better parenting. A model is presented to foster earlier change and better interaction between men and social
\end{abstract}


workers. Effective child protection work with men can come with empathic relationship building and more routine direct contact.

Keywords: Fathers, Men, Assessment, Child Protection

\section{Implications Statement}

- Engaging fathers should be part of everyday practice in child protection and not an unmanageable task.

- Most men in child protection pose both a risk and a resource for their child. The actual and potential benefits they bring to their child should be discerned as well as any risks.

- When there is substantiated maltreatment it is crucially important that the children's fathers and father figures have been fully assessed.

Children have a right to family life and a right to be free from maltreatment (Human Rights Act 2008; United Nations Convention on the Rights of the Child, 1989). Attempts to ensure both the child's right to family life and their right to live without abuse and neglect is a challenge for policy, for child protection assessment and for decision-making. Most maltreated children in the UK and other rich nations including the US and Australia, live at home with at least one of their parents (Campbell, Howard, Rayford, \& Gordon, 2015). Reviews show that this assessment challenge can often fail to take a child's father or father figure sufficiently into account (Gordon, Oliveros, Hawes, Iwamoto, \& Rayford, 2012; Maxwell, Scourfield \& Featherstone, 2012; Scourfield, Smail \& Butler, 2015). When parents are separated, children usually live with their mother and fathers may lose contact with their children and can also be lost to child protection and welfare agencies (Panter-Brick, Burgess, Eggerman, McAllister, Pruett \& Leckman, 2014; Campbell et al., 2015). Losing contact with separated fathers is perhaps less common in Australia, however, where $56 \%$ of children have at least monthly contact with the parent who is living elsewhere (ABS, 2015). 
There is an established literature about the overall benefits to children's healthy development of having a father involved in their lives (Lamb, 2010) and about the importance of the combined effects of mothers and fathers' involvement for children's wellbeing (Lamb \& Lewis, 2013). In the UK there are have been ongoing debates and concerns about the perceived absence of men in children's lives. The UK Centre for Social Justice used the expression 'man deserts' suggesting both absence and a lack of commitment from men to their children (Centre for Social Justice, 2013).

The advantages of father involvement are less clear when there are concerns about child maltreatment. In these circumstances it is particularly important that fathers and father figures are taken into account in any assessment of both the risks and the benefits they may bring to the child. Their inclusion is also important so that men are held accountable for their fathering role and sole responsibility for parenting does not rest with women as mothers. These historic gender inequalities in parental child care responsibilities are well known in Australia as well as elsewhere (Tehan \& McDonald, 2010, Fletcher, 2008; Doucet, 2004; 2009; Featherstone \& Peckover, 2007).

Studies about parental engagement in child protection can be (unconsciously) gender blind, failing to distinguish between male and female parents (for example Darlington, Healy \& Feeney, 2010). This can be the case even when studies make specific efforts to include men, for example in a UK study by Ghaffar, Manby, \& Race (2012). This lack of differentiation between mothers and fathers is also evident in legislation, policy documents and guidance whenever the term 'parent' is used (Philip \& O'Brien, 2016).

Although it is good practice, not all interventions aimed at common child protection concerns for men, for example domestic abuse or substance misuse, routinely address fatherhood or the impact of these concerns on children. For example, in a recent 
US study of substance misuse treatment programmes for men, addressing parenting for substance-using men was given scant attention (Stover, Carlson, Patel, \& Manalich, 2018). Surveys of men in residential substance misuse treatment, however, found that they thought about their children all the time, suggesting an enduring identity as a father (in Stover et al 2018). Children may feel differently than their fathers about his fathering role. Lamb, Humphreys, \& Hegarty's (2018) Australian study of children's views about their fathers' domestic abuse found that a small number of young people did not want any further contact with their father, although most said they would consider this if their father made substantial changes to both his behaviour and attitudes. Even those young people who did not want an ongoing relationship with their father still wanted reparation from him so that they could move on with their lives.

Numerous authors in Australia and beyond have demonstrated the ways in which men are marginal in child protection and have suggested ways to ameliorate this (Berlyn, Wise \& Soriano, 2008; Fletcher, 2008; Tehan \& McDonald, 2010; Zanoni, Warburton, Bussey, \& McMaugh, 2013; 2013; Scourfield et al., 2015). However, Scourfield's early categorisation of practitioners' perceptions of men as a threat, as no use, as irrelevant or as absent, can still have resonance for contemporary practice (Scourfield, 2003; 2006).

This paper shows that in spite of the difficulties in engaging fathers, practitioners are able to create working relationships with men where the balance of risks and strengths they bring can be respectfully assessed. The study which is the focus here, considered the nature and extent of involvement of father/father figures in assessments and in the lives of children in three areas in England for whom maltreatment had been substantiated. The ways in which fathers and father figures were perceived as risks or resources to their 
children is presented as a model to encourage better, more dynamic interaction between men and social workers.

\section{Methods}

The key aims of the study were to provide insights into fathers' and father figures' engagement as caregivers and men with both their child and with social workers in cases of substantiated maltreatment. These insights, garnered primarily from the men themselves, were intended to guide future practice and address some of the barriers to men's engagement and involvement in child protection. The central innovative aspect of the project was a prospective qualitative longitudinal (QL) study of 35 men's experiences of child protection processes which involved in-depth interviews and regular, ongoing contacts with participating men. This was contextualized by primarily quantitative data about men's involvement from a separate, retrospective, case file analysis of 150 child protection cases. This contextualisation captured more variation than is possible in a qualitative sample. In addition, we held focus groups with social workers and managers in the participating local authorities to test out findings and gain professionals' perspectives on the barriers and facilitators of working with men in child protection.

The examination of 150 children's files explored father involvement with their child and in child protection over 12 months from Jan 2014-Jan 2015. Data were collected from the first and consecutive 50 child protection cases in three separate local authorities in England. Child protection status was defined by the substantiation of abuse at a comparable time for children across all three authorities (a new child protection plan made at the Initial Child Protection Conference [ICPC]). A common template was used to garner information from each file systematically. Data were coded into the Statistical Package for the Social Sciences (SPSS) and descriptive statistics produced. 
The prospective, qualitative longitudinal study of 35 men, followed their lives and involvement with child protection, intensively, in real time over twelve months. This entailed 'walking alongside' participants through their lived experience to provide a 'close up shot of real lives with a focus on plot, story line, turning points and defining moments' (McLeod \&Thomson, 2009, p61; Saldana, 2003). With the support of social workers and child protection conference chairs, we recruited the 35 men shortly after a child protection plan had been made for the child at the Initial Child Protection Conference (ICPC). At the end of the 12 months we were still in contact with 28 men and had lost contact with seven.

Although the men came from the same three local authorities as the contextual case file sample, they were not part of or recruited from the case file sample because it was necessary to have a common, early, starting child protection reference point, which the ICPC provided. Men from the retrospective file sample (if still in child protection) would have been at a 'late' stage of involvement, so opportunities to understand early engagement would have been lost.

Initial and end of year in-depth interviews with each QL respondent were undertaken, supplemented by regular (mostly monthly) contacts with the same dedicated researcher usually by SMS text and phone. Interviews were semi-structured using, for example, timelines and genograms at first interview with the structure of final interviews informed by the on-going analysis. At both interviews men were asked about the child protection plan and often showed the researcher a copy of the CP plan or other assessment. Interviews were recorded and transcribed, while other contacts were captured in researcher notes. 
The rich data gathered were digitised, summarised and indexed. Each indexed case was independently coded by one other researcher from the team and cross checked by the third team member. Analysis was aided by the use of NVivo frameworks (NatCen,2014). Data were sorted and analysed by each man's individual life trajectory and his pathway through services and by different child protection themes (see figure 4 for these themes). Data were analysed as they arrived to form a cumulative picture which was discussed and checked at regular team analysis sessions.

Profiles of the 139 fathers or caregiving men from the 150 files were compared with the sample of 35 men to check that the qualitative sample was reasonably representative of men in child protection in these local authority areas. Table 1 shows that in many respects the two samples were similar, although more of the 35 men were resident with their children and the children's mother.

\section{PUT TABLE 1 ABOUT HERE}

The study was funded and supported by the Nuffield Foundation. Ethics approval was granted by the School of Social Work ethics committee at the University of East Anglia and all three local authorities. Findings from the overall study are available in the research report (Brandon, Philip \& Clifton, 2017) and in Philip, Clifton \& Brandon, 2018).

\section{Findings}

\section{Are Men Absent or Involved in Children's Lives?}

The case files showed that men involved in child protection cases were present rather than absent in the lives of the 150 children whose local authority files we analysed. One year on, only 39 of the 139 caregiving men were no longer in contact with the child, showing that it was much more common for men to stay in touch than become absent. 


\section{PUT FIGURE 1 about here}

The categories of contact shown in Figure 1 are drawn from the work of Poole, Speight, O'Brien, Connolly, \& Aldrich, (2016) where regular contact is defined as seeing the child at least monthly while distance/infrequent contact means seeing the child less than monthly. Family lives showed some fluidity, with changes of family membership over the year of the file search. Although fathers appeared more mobile than the children's mothers, moving in and out of families, for many men separation had not presented an insurmountable barrier to keeping in contact, as Figure 1 shows.

\section{Are Men Assessed and Involved in Child Protection Processes?}

For the most part, only basic information about the 139 men in a caregiving role was present in files. Overall, the files lacked detailed information about men's lives, including their relationship networks, health, employment housing and economic status. Any information about men mostly identified problems with alcohol, being the perpetrator of domestic violence and being a risk to children.

Nevertheless, files showed that there were often attempts to include fathers and men in decision making, though with differing degrees of persistence. The men that social workers most often engaged with, or had knowledge of, were birth fathers living with the child, rather than separated fathers, in keeping with the US study by Campbell et al (2015). Of the 58 caregiving men who were invited to the initial child protection conference, 41 were birth fathers. Only 13 of these birth fathers declined to attend and once they had become engaged in formal child protection processes, they tended to stay involved throughout the year. This suggested tenacity both on the part of the men and the practitioners assisting their participation. 
Whilst there could be legitimate reasons for not inviting men to the conference, an invitation rate of $42 \%$ for the 139 caregiving men is a low baseline for early inclusion.

\section{Understanding the 35 QL Men's Perspectives and Lives}

There was insufficient information to know about the lives of the 139 'caregiving' men in the children's files or the way they were linked to the child maltreatment concern. Much better information was available from the QL study of 35 men. Detailed contacts with these men over the year offered insights into their lives and into how they felt they were perceived by social workers, at the start of the formal child protection process, and whether or how this changed over time.

The circumstances and preoccupations that the 35 men brought with them provided an essential context to how and whether they engaged with the demands of the child protection system and how they managed their fathering role. Most (24/35) were living economically precarious lives with diminishing access to state welfare benefits, with insecure work and increasing debt. Fifteen were not in employment and only seven men had regular, contracted, work but often this was poorly paid so that balancing debt and financial commitments was for most ' a bit of a struggle'. Well over half of the men (20/35) reported a significant illness, disability or other impairment which for twelve of them included mental health challenges such as depression, anxiety, chronic stress, substance misuse, instances of self-harm and panic attacks.

The complex networks of relationships surrounding fathers meant that men were continually balancing, sometimes conflicting, demands to maintain their income, meet the needs of their children, and their current intimate relationships, whilst negotiating contact with ex-partners and non-resident children. 


\section{Positioning Men in Child Protection}

Our analysis of social workers' positioning of men in child protection is primarily from the perspective of the men and combines men's accounts of their interactions with social workers, and our knowledge of the trajectory of each case, in relation to meetings, decisions or actions taken about the status of the case, the child's care, and the man's own involvement. It is our interpretation of men's positioning rather than a corroborated truth (which was not our aim within this qualitative research). We developed six main 'positioning' categories from the file analysis of 150 child protection cases which we tested and applied to the 35 men studied in depth to arrive at a best fit for each man. These were 'sense checked' and discussed in the focus groups held with social workers.

At the beginning of the year when the maltreatment had been first substantiated, ten men were under direct suspicion for the harm to the child and seven men were under scrutiny for their capacity to care for the child (as either a resident or non-resident father). A further nine men already had a history of violent offending or of previous harm to a child. The remaining nine men were seen as a protective or partly protective factor at this early stage.

\section{PUT FIGURE 2 about here}

The six categories and changes over the year are shown and defined in Figure 2. The movement and the direction of flow between the categories varied, with some cases being more dynamic than others as shown in Figure 3.

\section{Moving Towards Greater Involvement}


The greatest flow of movement occurred in a positive direction, towards men becoming recognised or accepted as 'good enough' fathers, or as a 'safe pair of hands'. Eleven men spoke of a positive shift in social workers' perceptions and behaviour towards them, with most moving away from being 'in the frame' or 'on trial'. Two also moved from being 'on the fringe' as separated non-resident fathers, to taking on full-time care of their child.

Key factors that contributed to these positive moves, as men reported them, were social workers recognising the protective or positive aspects of men's parenting and/or social workers' verifying men's concerns about mothers' care of the child. This positive assessment of men's parenting mostly occurred within a couple relationship, but also for two men, as separated parents.

People take the woman's side... how many men end up with their children living with them? They automatically assume that the children will live with their mum. (Kyle 'on trial' moving to 'good enough')

Just as in the US study of father involvement by Campbell et al (2015), social workers' changed approach to working with the father, was often linked to a change in their view of the mother's needs, capacity, or culpability and to taking the fathers' concerns about the mother's parenting more seriously. In the six cases where fathers became the main carer for their child, three men talked about previous periods of child protection and longer histories of their raising concerns with social workers or other professionals (with little happening as a result).

Everyone assumes it's the father's fault. They don't even ask... that should change. (Henry 'on trial' moving to 'good enough') 
Within the group of men who moved into the category of 'good enough' were also three fathers who felt they were considered only as a 'last resort' once the case was on the edge of care proceedings.

She said she can't cope again and I got a phone call from the social saying 'do we have your permission to take the kids in care'? ... and I said, 'No, I will come and get him' (Brandon 'in the frame' moving to 'good enough')

\section{Moving to the Periphery}

A second notable pattern was the movement of men away from involvement in the case and potentially from the child. Four men abdicated their role as fathers when held responsible for their child's maltreatment and disengaged from the child protection system. One father rejected social workers' concerns about his care and turned his anger against his now estranged 'obnoxious' daughter, who was in care.

We have done everything for our daughter and yet she is actually saying you have not done anything for me you hate me. (Asif, 'in the frame' moving to 'on the fringe')

Three further fathers remained on the periphery for the duration of the case.

Separated fathers were more likely to feel peripheral as time went on particularly if they felt that their ongoing role and relationship with the child had not been considered as part of the intervention. Another route to being more peripheral arose from antagonistic relationships between men and social workers, where a cycle of mutual suspicion and mistrust had become entrenched. Two such men expressed ambivalence towards social workers, challenging their credibility whilst also feeling let down or excluded. As a result, both detached themselves from involvement with the case, as an act of resistance. Once a man was considered peripheral, either via non-residence or by being seen as 'difficult', the chances of his re-engagement and re-assessment were often slim. 


\section{Staying 'Marked'}

The group of men least likely to report or experience any positive change in their relationships with social workers and with their child were the 'marked men'. Men with a history of losing previous children to care, or of violence or domestic abuse offences, were unlikely to move out of this category over the year. Nine men entered the child protection process as 'marked' and by the end of the 12 months, there had been no positive shift in how social workers' perceived seven of them.

Social services became involved when he was born, based on my past history. So it was basically they are brandishing me and tarnishing me with the same brush. (Mark remained 'marked')

Four of these fathers experienced the court ordered removal of a subsequent child and two more were resisting attempts to restrict their involvement with the child. Three fathers told us they could not risk getting close to a new baby because, they are going to take the baby anyway. (Shane)

I hate Social Services they have ruined my life from the minute I turned 15 ...It's not that I don't see where they're coming from, it's just like being stuck in this way for ages, no one has helped me since, no one ever tried. (Dale, remained 'marked')

Two men who were 'marked' at the start withdrew from the study after the first three months, and one other man died from complications linked to his drug misuse. Despite the lack of movement out of this category, all but one man described an assessment process or conditions for his involvement set by the child protection plan. However, whilst this suggests that 'marked men' were given some opportunity to demonstrate change, most felt that their chances of 'passing' assessments were slim, and some felt threatened or 'goaded' by the process. For this group of men, a productive 
working relationship with the social worker was never established, and this tended to produce two different strategies or responses. One was to resist the process, either by open challenge or by avoidance. The second was to submit to the child protection process, as further confirmation of failure as a father and as a man.

One exception to this was a father, who despite experiencing the child protection process many times in his life and having a second child removed from his care, managed to sustain a viable moral identity and narrated his culpability in a way which did not render him shamed or entirely guilty (Gibson, 2015). Whilst he did not move out of the category of 'marked men', he moved himself on with an apparent resilience and some optimism.

\section{Towards a Model of Men's Movement through Child Protection}

Whilst a steady flow of fathers appeared to be accepted as 'good enough', the experience of how, and when this process happened differed and tended to be facilitated or stalled by the interactions between social workers and men. Birth fathers, who were living with their children and the child's mother were more likely to be included in assessments (and included early). Separated non-resident fathers were much more likely to either move to or remain on the periphery of the case, unless they were highly active in claiming their entitlement to fatherhood.

\section{Interactions Between Men and Social Workers}

One way to understand the barriers and enablers to movement through the child protection system is as a form of gatekeeping for men. Gatekeeping is defined as an interactive series of encounters between men and social workers within which positive change requires the participation of both parties (Trinder, 2008). Social workers are able to 
generate, or act on gate opening and gate closing opportunities for men's involvement as fathers, and men are also able to influence such opportunities arising, or consider their own response to these. The presence or absence, development or deterioration of a working relationship with the social worker was central to this process. Most men did want a relationship with the social worker and acknowledged the two-way nature of the encounter. They wanted to be listened to and be taken seriously and wanted the relationship to have some reciprocity. They also wanted (often practical) support.

A 'bearable' working relationship, had enough mutual respect, receptiveness, flexibility and reliability to generate some shared understanding as a basis to discuss the man's involvement in the child's life. Barriers to forming working relationships included men and social workers mirroring a sceptical view of each other, with each describing the other as 'hard to reach', evasive or defensive. However, things could, and did, change for most men. Most men either described 'ups and downs' in their relationship, or could recall at least one previous social worker with whom they had worked well. Yet a significant minority of men (including some but not all of the 'marked men') experienced this mutual scepticism and mistrust as reinforcing, and did not develop any constructive relationship with the social worker.

We developed a model of interaction between men and social workers (Figure 4) which shows how different types or degrees of father engagement may emerge with three kinds of engagement with fathers. Although 'strategic exclusion' may be necessary in some cases, when this occurs, opportunities can be lost for fresh thinking and rehabilitative possibilities, particularly for 'marked men' who have lost previous children to care (Broadhurst \& Mason, 2017). Caseload pressures may also encourage a tendency for social workers to avoid interaction with men and thus settle for 'passive inclusion' (Campbell et al, 2015) yet when there is 'active involvement' the results can be 
transformative. Factors that may help or hinder the development of these constructive working relationships, include managing early contacts or 'opening gambits' well. They also require social workers to have the capacity to 'tolerate' men's emotions, and be flexible and reliable. Thus a combination of organisational and attitudinal factors influence the gatekeeping mechanisms for men in child protection.

\section{PUT FIGURE 4 about here}

\section{Discussion}

Fathers who faced and posed the greatest challenges for involved fatherhood were the 'marked men' who were the most likely to actively reject or absent themselves from child protection involvement. The rehabilitative issues for these marked men were rarely addressed by children's services, and the men's appearances in child protection and care proceedings were often cyclical.

The assessment of men in files tended to focus on whether they posed a risk to their child and rarely took into account any strengths they brought to the family dynamic or benefits they brought to the child. This narrow gaze produces little knowledge about men's lived experience and what they are actually doing as father and father figures. Paying attention to men as people with needs and concerns of their own, in contrast, produces an understanding that is highly relevant to the assessment and to discerning and supporting men's capacity to be effective fathers.

The lack of depth and context in the assessments of men has been found more widely, for example in child welfare in the US (Campbell, et al, 2014). Yet the positive change we found in the categorisation of social workers' perceptions of men moving towards greater involvement, shows that in practice, social workers are able to connect 
with men. In order to assess and evaluate the balance of resource and risk of harm a father may present, some social workers recognised the need to understand men's lives as fathers, but were rarely able to devote the time to this that was needed. Seeking a full picture of the background, relationship dynamics, wellbeing, and current circumstances of the child's father or father figure eats into the limited time available in current child protection practice. Workers need organisational support and recognition of the importance of keeping in direct contact with men to help fathers stay involved in child protection (Scourfield et al., 2015).

Professional curiosity about men's lives, their perspectives and narratives produces the learning needed for a rigorous approach to assessment. This approach takes account of the benefits to the child's wellbeing fathers may bring, as well as any harm they may pose (Featherstone \& Peckover, 2007). Without knowing the father well, this balancing of risk and benefit cannot be rigorously undertaken. The skills and willingness to 'hold' or take a chance on this combination of risk and resource is traditionally more present in practice with mothers than fathers, where there may be either a lack of confidence or a lack of willingness to practice in this way (Doucet 2009; Maxwell et al, 2012).

The problem of the lack of engagement between men and social workers is not insuperable. Negotiation and encouragement between workers and men may be needed for fathers to participate more fully in the work to protect the child. Similarly, men may need support to stay involved with their child. Active involvement can be seen as part of a strengths-based approach where honest communication about child protection concerns does not preclude recognising the positive contributions a father can, or could make (Turnell, 2012). More widespread involvement at the important early stage would, arguably, not only produce a better, more accurate, assessment of the risks and strengths of 
men closely connected to the child, but also foster their ongoing participation in child protection.

Social workers have a key role as gatekeepers with the opportunity to build better relationships with fathers. Both fathers and workers can recognise their own responsibility for relationship building. Either, or both social workers and fathers, can be agents for change in the way that working relationships are developed or stalled. Focusing on this interactivity and dynamism is important for practice because it can challenge longstanding assumptions about father 'absence', 'difficulty' or 'disengagement'.

\section{Limitations}

One limitation of the study is that it focuses on the views of fathers not children. The limitations of time and funding precluded involving children which we justified because knowledge of the lives of men and their views in child protection are so scarce. Another limitation of our sample of 35 men is that it under-represents men not invited to, or not attending, the initial child protection conference. This means findings may reflect the experiences of more involved fathers. However, a further implication is that the barriers to engagement and relationship building are likely to be even greater for men who are missing from the initial conference. Another area where the sample of 35 men is not diverse is in relation to ethnicity (all but three participants were White British). Although the sample did reflect the ethnic profile of the local authority areas, we had few opportunities to illustrate this aspect of diversity. In addition, we were not able to recruit any fathers under the age of twenty although some of the 35 men were in their late teens when they first became fathers. 


\section{Conclusion}

Engaging fathers should be seen as everyday practice in child protection and not as an unmanageable task or as one manager expressed it 'an additional can of risk'. Better engagement may require organisations to tackle structural and cultural barriers to fathers' involvement. This includes challenging deep-rooted assumptions about gender and parenting, where the father-child relationship is often seen as secondary and where the child protection system tends to prioritise mothers over fathers. Workers need confidence that managers will support them in this and managers themselves need to challenge riskaverse, procedurally driven, culture and practice.

\section{Acknowledgement}

This project was funded by the Nuffield Foundation, but the views expressed are those of the authors and not necessarily those of the Foundation.

\section{References}

Australian Bureau Statistics. (2015). Family characteristics survey, 2012-13, Catalogue no.4442. Canberra: Australian Institute of Family Studies, Australian Government. Retrieved 05.04.2019.https://aifs.gov.au/facts-and-figures

Berlyn, C., Wise, S., \& Soriano, G. (2008). Engaging Fathers in Child and Family Services: Participation, Perceptions and Good Practice, Family Matters, 80, 37-42. 
Brandon, M., Philip, G and Clifton, J (2017). Counting Fathers In' Understanding men's experiences of the child protection system. Norwich: University of East Anglia. www.uea.ac.uk/centre-research-child-family.

Broadhurst, K., \& Mason, C. (2017). Birth parents and the collateral consequences of child removal: towards a comprehensive framework. International Journal of Law, Policy and the Family, 31(1), 41-59.

Campbell, C., Howard, D., Rayford, B.S., and Gordon, D.(2015). Fathers Matter: involving and engaging fathers in the child welfare system, Child and Youth Services Review, 53, 84-91.

Centre for Social Justice, (2013). Fractured Families: Why Stability Matters. Downloaded from http://www.centreforsocialjustice.org.uk/core/wpcontent/uploads/2016/08/CSJ_Fractured_Families_Report_WEB_13.06.13.pdf on 16 August 2017.

Darlington, Y., Healey, K., \& Feeney, J. (2010). Challenges in implementing participatory practice in child protection: A contingency approach. Children and Youth Services Review, 32 (7), 1020-1027.

Doucet, A. (2004). "Fathers and the Responsibility for Children: A Puzzle and a Tension”. Atlantis: A Women's Studies Journal, 28(2); 103-114.

Doucet, A. (2009). Gender equality and gender differences: parenting, habitus, and embodiment (The 2008 Porter Lecture). Canadian Review of Sociology, 46 (2), $103-121$. 
Featherstone, B. \& Peckover, S. (2007). Letting them get away with it; fathers, domestic violence and child welfare. Critical Social Policy, 27 (2), 181-202.

Fletcher, R. (2008). Father-inclusive practice and associated professional competencies, (AFRC Briefing No. 9), Melbourne: Australian Institute of Family Studies.

Ghaffar, W., Manby, M., \& Race, T. (2012). Exploring the experiences of parents and carers whose children have been subject to child protection plans, British Journal of Social Work, 42 (5) 887-905.

Gibson, M. (2015). Shame and guilt in child protection social work: new interpretations and opportunities for practice, Child \& Family Social Work, 20, 333-343.

Gordon, D., Oliveros, A., Hawes, S., Iwamoto, D \& Rayford, B. (2012). Engaging fathers in child protection services: A review of factors and strategies across ecological systems, Children \& Youth Services Review, 34, 1399-1417.

Lamb, K., Humphreys, C., and Hegarty, K. (2018). "Your behaviour has consequences": Children and young people's perspectives on reparation with their fathers after domestic violence, Children and Youth Services Review, 88,164-169.

Lamb, M.E. (2010). The Role of the Father in Child Development. Hoboken. New Jersey: John Wiley \& Sons.

Lamb, M.E., \& Lewis, C. (2013). Father-child relationships. In Cabrera, N \& TamisLemonda, C.S. (Eds.) Handbook of father involvement: Multidisciplinary perspectives. New York: Routledge. 
Maxwell, N., Scourfield, J. \& Featherstone, B. (2012). Engaging fathers in child welfare services: A narrative review of recent research evidence. Child and Family Social Work, 17 160-169.

McConnell, N and Taylor, J. (2016). Evaluating programs for violent fathers; challenges and ethical review, Child Abuse Review, 25: 183-191 (2016) DOI: 10.1002/car.2342.

McLeod, J. \& Thomson, R. (2009). Researching Social Change. London: Sage.

NatCen (2014). Frameworks in NVIVO manual- Step by step guide to setting up Framework matrices in NVIVO. London: NatCen Social Research.

Philip, G., Clifton, J., \& Brandon, M. (2018). The Trouble With Fathers: The Impact of Time and Gendered-Thinking on Working Relationships Between Fathers and Social Workers in Child Protection Practice in England. Journal of Family Issues. https://doi.org/10.1177/0192513X18792682.

Philip, G., \& O’Brien, M. (2016). Are interventions supporting separated parents father inclusive? Insights and challenges from a review of programme implementation and impact, Child and Family Social Work doi:10.1111/cfs12299

Poole, E, Speight, S, O'Brien, M, Connolly, S \& Aldrich, M. (2016). Who are NonResident Fathers? A British Socio-demographic profile. Journal of Social Policy, 45 (2) $223-25$.

Saldaña, J. (2003). Longitudinal qualitative research. New York: Altamira Press.

Scourfield, J. (2003). Gender and child protection, Basingstoke: Palgrave. 
Scourfield, J. (2006). The challenge of engaging fathers in the child protection process. Critical Social Policy, 26(2) 440-449.

Scourfield, J., Smail, P., \& Butler, D. (2015). A Systemic Approach to Improving the Engagement of Fathers in Child Safeguarding. Child Abuse Review 24: 129-139.

Stover, C., Carlson, M., Patel, S., \& Manalich, R. (2018). Where's Dad? The Importance of Integrating Fatherhood and Parenting Programming into Substance Use Treatment for Men, Child Abuse Review. 27: 280-300.

Tehan, B., \& McDonald, M. (2010). Engaging fathers in child and family services, CAFCA Practice Sheet, Melbourne: Australian Institute of Family Studies.

Trinder, L. (2008). Maternal Gate Closing and Gate Opening in Post-divorce Families, Journal of Family Issues, Vol 29 (10), 1298-1324.

Turnell, A. (2012). The Signs of Safety Workbook. Resolutions Consultancy. Downloaded from www.signsofsafety.net on 16 August 2017.

Zanoni, L., Warburton, W., Bussey, K., \& McMaugh, A. (2013). Fathers as 'core business' in child welfare practice and research, Children \& Youth Services Review, 35, 1055-1070. 
Table 1: Comparison of 139 Caregiving Men in File Study and 35 Men in QL Sample

\begin{tabular}{|c|c|c|}
\hline & $\begin{array}{c}139 \\
\text { Caregiving men } \\
\end{array}$ & 35 QL men \\
\hline Men's age range & $16-64$ years & $21-59$ years \\
\hline \multicolumn{3}{|l|}{ *Men's ethnicity } \\
\hline White British & $66(90 \%)$ & $32(91 \%)$ \\
\hline White other & $7(10 \%)$ & $1(3 \%)$ \\
\hline Asian & - & $2(6 \%)$ \\
\hline \multicolumn{3}{|l|}{ Relationship with child } \\
\hline Birth father & $71(51 \%)$ & $29(83 \%)$ \\
\hline Step father/social father & $32(23 \%)$ & $4(11 \%)$ \\
\hline Grandfather & $14(10 \%)$ & $2(6 \%)$ \\
\hline Other male relative & $18(13 \%)$ & - \\
\hline 'Other' men & $4(3 \%)$ & - \\
\hline \multicolumn{3}{|l|}{ Living with the child? } \\
\hline Resident with child & $39(28 \%)$ & $16(46 \%)$ \\
\hline Non-resident & $40(29 \%)$ & $16(46 \%)$ \\
\hline Part-resident/shared care & $40(29 \%)$ & $3(8 \%)$ \\
\hline Unclear/not recorded & $20(14 \%)$ & - \\
\hline \multicolumn{3}{|l|}{$\begin{array}{l}\text { Relationship with child's } \\
\text { mother }\end{array}$} \\
\hline Married or co-hab partner & $28(20 \%)$ & $13(37 \%)$ \\
\hline Non-res partner/boyfriend & $13(9 \%)$ & - \\
\hline Separated/divorced & $57(41 \%)$ & $18(51 \%)$ \\
\hline Non-resident couple & - & $2(6 \%)$ \\
\hline Male relative & $25(18 \%)$ & $2(6 \%)$ \\
\hline Unclear /not recorded & $16(12 \%)$ & - \\
\hline \multicolumn{3}{|l|}{$\begin{array}{l}* * \text { Status of case after } 12 \\
\text { months }\end{array}$} \\
\hline CP plan in place & $36(26 \%)$ & $5(14 \%)$ \\
\hline Services below CP threshold & $46(33 \%)$ & $8(23 \%)$ \\
\hline Closed case & $37(27 \%)$ & $10(29 \%)$ \\
\hline $\begin{array}{l}\text { Legal order (eg care order, } \\
\text { special guardianship order) }\end{array}$ & $35(25 \%)$ & $6(17 \%)$ \\
\hline $\begin{array}{l}\text { Unclear (respondent } \\
\text { withdrawal from study) }\end{array}$ & - & $7(20 \%)$ \\
\hline
\end{tabular}

* ethnicity was recorded for only 80/139 caregiving men

** percentages sum to over 100 because of overlap with legal order 
Figure 1 Contact Between the 139 Connected Men and the 150 Children, at Time of Initial Child Protection Conference (ICPC) and One Year on $(n=139)$

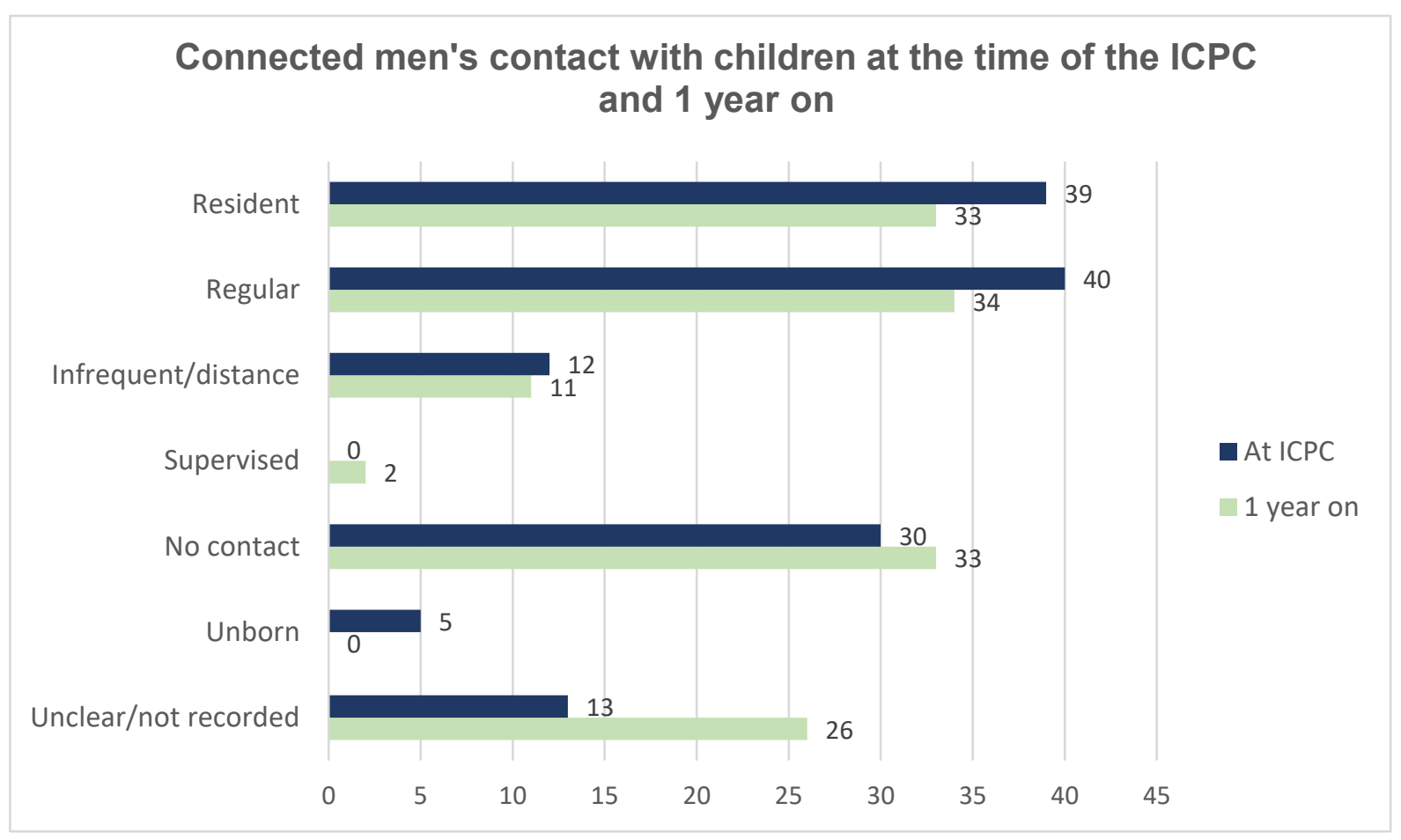


Figure 2. Social Workers' Positioning of Men in Child Protection at Time 1 (at Initial Child Protection Conference) and Time 2 (12 months later)

\begin{tabular}{|c|c|c|c|}
\hline $\begin{array}{l}\text { Category or } \\
\text { sub-group }\end{array}$ & $\begin{array}{l}\text { Time } 1 \\
\mathrm{~N}=35\end{array}$ & $\begin{array}{l}\text { Time } 2 \\
\mathrm{~N}=\mathbf{2 8}\end{array}$ & Definition \\
\hline $\begin{array}{l}\text { Safe pair of } \\
\text { hands }\end{array}$ & 1 & 3 & $\begin{array}{l}\text { Men whose care is deemed positive } \\
\text { and protective and/or is tried and } \\
\text { trusted. }\end{array}$ \\
\hline $\begin{array}{l}\text { Good } \\
\text { enough }\end{array}$ & 3 & 8 & $\begin{array}{l}\text { Men whose care is seen as } \\
\text { acceptable, though there may be a } \\
\text { perceived need to monitor over time }\end{array}$ \\
\hline On trial & 7 & 1 & $\begin{array}{l}\text { Men whose care is seen as needing } \\
\text { to be tested. The concerns may be } \\
\text { more or less serious. }\end{array}$ \\
\hline In the frame & 10 & 2 & $\begin{array}{l}\text { Men who are under suspicion for the } \\
\text { child protection incident and who are } \\
\text { the main focus of concern. }\end{array}$ \\
\hline On the fringe & 5 & 7 & $\begin{array}{l}\text { Men who are seen as peripheral to } \\
\text { the case, and whose involvement is } \\
\text { not the focus of the child protection } \\
\text { plan. }\end{array}$ \\
\hline 'Marked men' & 9 & 7 & $\begin{array}{l}\text { Men who have past removals and/or } \\
\text { offending histories in relation to DVA } \\
\text { or other violence. Seen as high risk. } \\
\text { The term 'marked' is used to denote } \\
\text { the stigmatising effect of such } \\
\text { histories and their impact on men's } \\
\text { futures as fathers. }\end{array}$ \\
\hline
\end{tabular}


Figure 3. Men's Movement through the Child Protection System

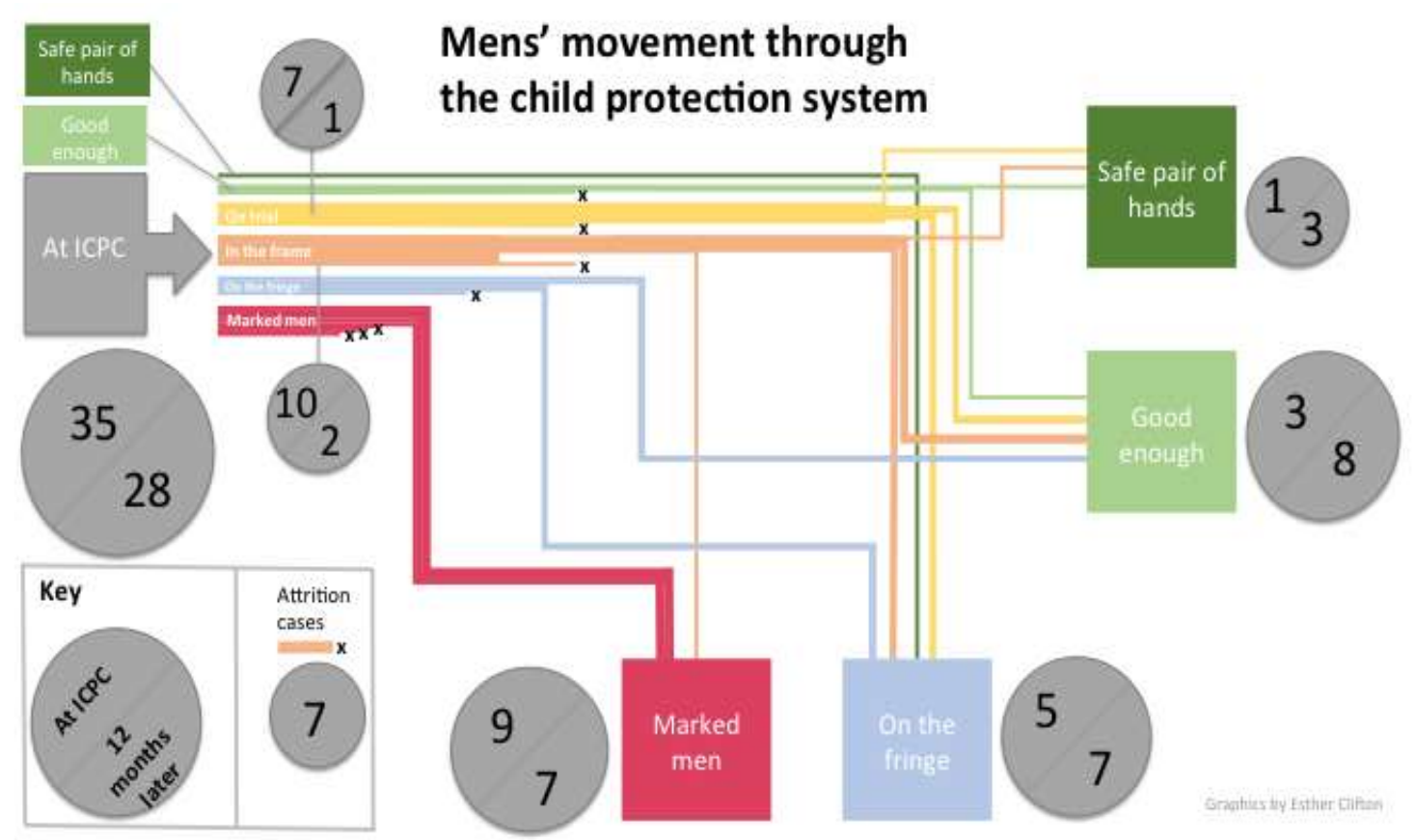


Figure 4: A Model of Interaction Between Men and Social Workers

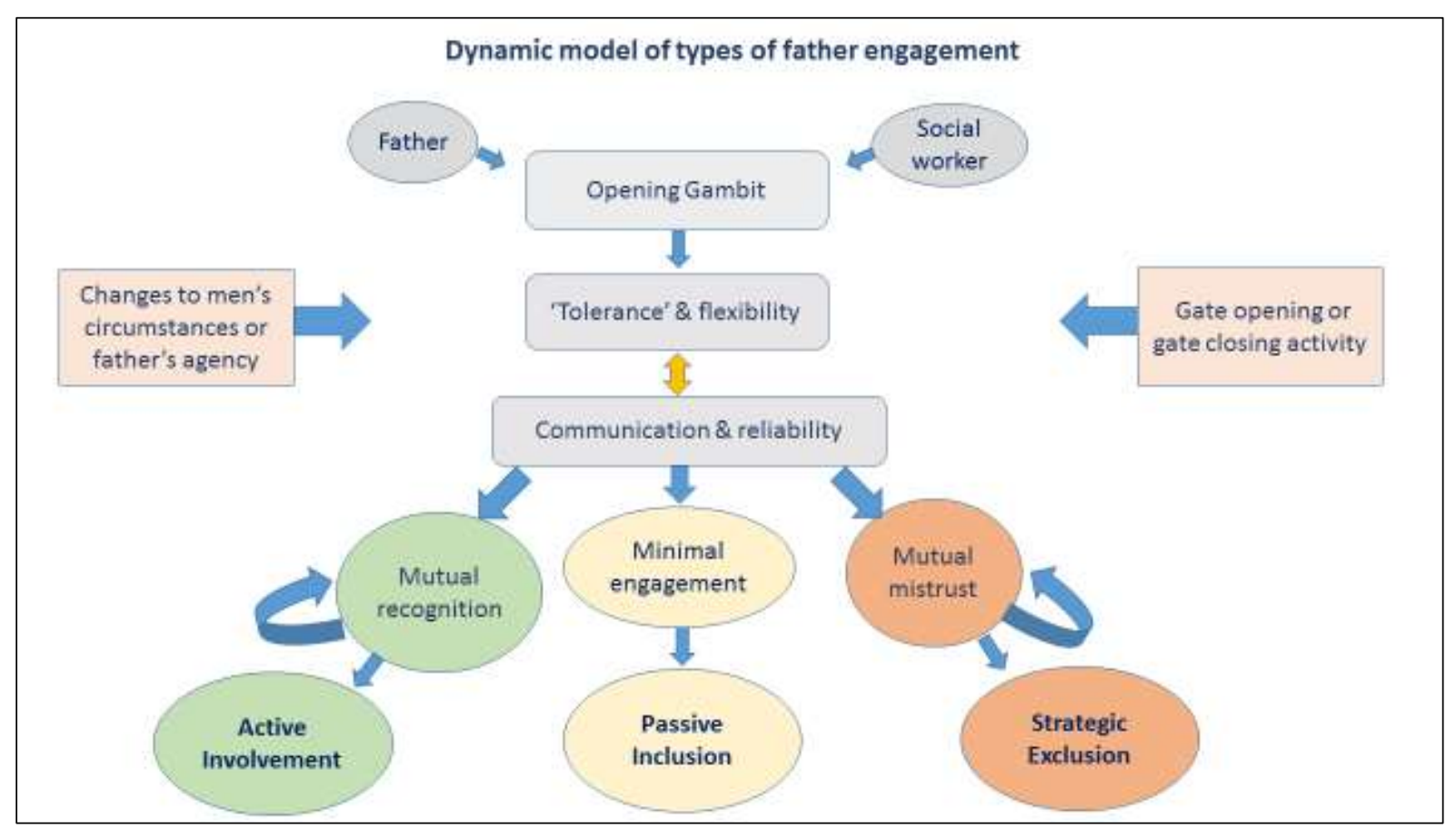

